\title{
Robust Optimization for Performance-Based Budget Allocation at Payam Noor University
}

\author{
Mohammad Mehdi Nasrabadi ${ }^{1}$, Elham Sharifi Rasouli ${ }^{2,}$,, Marziyeh Sharifi $^{3}$ \\ ${ }^{1}$ Department of Matematical Science, Payam Noor University, Birjand, Iran \\ ${ }^{2}$ Graduated Industrial Engineering, Alghadir Non-govenment Institution, Tabriz, Iran \\ ${ }^{3}$ Graduated Operation Research, Payam Noor University, Birjand, Iran
}

Email address:

m_m_nasrabadi@yahoo.com (M. M. Nasrabadi), elham.sharifi63@yahoo.com (E. S. Rasouli), sharifimarziye@yahoo.com (M. Sharifi)

${ }^{*}$ Corresponding author

\section{To cite this article:}

Mohammad Mehdi Nasrabadi, Elham Sharifi Rasouli, Marziyeh Sharifi. Robust Optimization for Performance-Based Budget Allocation at Payam Noor University. American Journal of Applied Mathematics. Vol. 4, No. 6, 2016, pp. 310-315. doi: 10.11648/j.ajam.20160406.17

Received: October 10, 2016; Accepted: December 29, 2016; Published: January 3, 2017

\begin{abstract}
Budget allocation is a central problem in universities and research centers. Recently, Payam Noor University (PNU) has used a performance-based approach to allocate budget between proposed projects. Mathematically speaking, this can be modeled as an optimization problem, but in practice the parameters of the problem are subject to uncertainty and are not well-known in advance. This paper uses robust optimization to deal with uncertainty in budget allocation and present numerical results. Our results demonstrate the performance of robust optimization as an effective way to address uncertainty in budget allocation.
\end{abstract}

Keywords: Linear Programming, Robust Optimization, Uncertainty, Budget Allocation

\section{Introduction}

In the current budgeting system in higher education institutions, budget is allocated based on several factors such as the number of students, faculty members and staff that means costs allocation which is carried out according to a standard volume and there is not any distinction among costs of different fields of study for students. Also, the cost of some courses is eliminated through extra resources by organizing other courses that require improving the control method sand financial resources management. This can cause universities focus more on efficiency and effectiveness of their financial resources and the only way to achieve these objectives is establishment of performance-based budgeting order.

Performance-based budgeting is a system of planning, budgeting and evaluating that focuses on the relation between funding costs and the expected results. In this context, various kinds of administrative units are accountable based on specific standards as performance indicators. Cost priorities and performance evaluation are evaluated in the context. PBB is the annual performance program with an annual budget that shows the relation between the budget allocation to the program and the results of the implementation of the program. This means that through a certain amount of expenditure paid in each program, a certain set of objectives must be provided. Not using of mathematical theories in government annual public budgeting causes confusion and inappropriate resource allocation. Certainly, if the activities and decision-making environment is not complicated, the use of mathematical models is not important. But when the number of decision variables, activities and aims increase, the importance of mathematical approaches becomes evident. Operation research or management science is a scientific and mathematical approach to solve this problem. The successful application of linear programming in research operation has been the greatest impact achieving optimal results for resource allocation problems [2].

In this way, the main objective of this study is to provide a programming model for funding university commensurate with the cost structure of the budget that can specify both the 
necessary budget for each program and subprogram and the amount of budget allocation to each unit and center according to the standards of the science ministry based on each students' fund per head.

\section{Problem Statement}

The budget in its present form is a strategic tool for government economic and financial discipline. Administrators cannot separate the budgeting at state universities from many items such as the environment in which they operate, economics and the public political environment. So the concept in budgeting and performance management for state universities need to consider certain factors such as government control, social accountability and funding through taxes. Performance-based budgeting is a system that formally connects increase in costs to increase in results. To accomplish this, it is necessary that the operational performance indicators be identified and has the ability to operate as well as be practical. Also agencies have to be more welcoming, so that they can determine the most efficient presentation method.

In this case, apart from those related to the effectiveness, reducing per capita resources dictates that universities use their available resources, to work more accurately and efficiently. Do not use quantitative and mathematical theories in schools where the program's annual budget, financial resources and credit costs are expected to be determined, confusion and lack of optimal resource allocation is available. Certainly, if the activities and decision making environment are not complicated, the use of mathematical models is not important. Extensive review of the literature on budgeting, especially at the university budget shows that so far no study has been done to investigate simultaneously the cost structure of academic programs, the dedicated fund to each of the units and the relationship between the two is not provided. The aim of this study is to suggest a model appropriate to the cost structure of each program and subprogram provided that the funds needed to determine based on their performance.

\section{Literature Review}

Today according to the importance of decision making in financial and strategic issues in many modern world organizations, application of intuitive and theoretical generalizations is replaced by quantitative decision making. In the 1940s George B. Danzig searched techniques for solving military planning. After World War II, research in operation entered into the business world. Linear programming was created as a mathematical model and quickly attracted-economics, mathematicians, statisticians and government institutions. John One Neumann in 1951 developed duality theory, Charness and Cooper [9] presented a model for the budget planning system, Lee and Shim [17] devised a model for zero-based budgeting and Min Hokey [14] provided an ideal model for planning.
PBB, which was applied for the first time after World War II in the budget reform in order to emphasize on product instead of input, was used in industrialized Countries and in the 1950s in America seriously. In America 1950-1951 fisical budget was prepared on the same basis. The recent reforms were not successful because of accounting errors and inappropriate indicators of performance. In the beginning of 1960s in America Department of Defense, planningbudgeting package was used. In the second half of the 1960s with the publication of a budgeting book by the UN, and the use of this system performance budgeting was reinforced, so that the organization for Economic Cooperation and Development (OECD) Report of year 2001 shows that 70\% of the member countries used this system.

The most important studies in the field of robust optimization are Sylvester's robust approach, Ben-Tal and Nemirovski [6], Bertsimas and Sim [8] and Ben-Tal and colleagues [3]. For budgeting in the public sector, Azar's model [1] and Najafi's model [15] were presented for budgeting with robust approach. Linear programming model with a robust approach to performance-based budgeting, Azar and colleagues [2], Caballero and colleagues [10], Lee's model [13] and Zanakis [18] are other researchers in the field of performance based budgeting with robust optimization.

\section{Theoretical Foundations}

For years, the issue of dealing with uncertainty in planning problems was considered by researchers and professional consultants. So far, several approaches in mathematical optimization problems for dealing with uncertainty and risk is developed i.e. phase planning. Uncertainties can affect the efficiency and feasibility issues. Usually the best estimated data used in the mathematical models is called nominal data. One of the recent approaches is robust optimization, Bertsimas and Sim's model is an interaction between efficiency and robustness. Their model is a linear model that modifies the conservative level of robust answers. In this study, according to uncertainty of upper-bound budget, they are defined as uncertain parameters that fluctuate in a symmetrical range, and by aid of Bertsimas and Sim's robust model, the nominal counterpart robust model is designed.

The performance-based budgeting adds saving and efficiency factors to the traditional aspects of budgeting. Classification of operations in PBB is in such a way that goals are clearly stated, budgeting, evaluation is easier, the relation between inputs and outputs is considered, and the results of the program performances are used as a scale for the next credit allocation. In order to calculate the efficiency of each unit, the Data Envelopment Analysis (DEA) was used.

\section{Methods}

This study discusses the university budgeting by providing a structure that involves both programs and activities carried out during the year and the costs of each unit. Due to legal 
restrictions in resource and expense allocation, some restrictions should be applied on allocation so that the solutions obtained through the model can be implemented. Also, due to uncertainty about the upper-bound budget, they are defined as uncertain parameters which swing around symmetrical intervals. First, we devise the certain performance-based budgeting model and then, according to Bertsimas and Sim' model, present the robust counterpart of the model, using PNU of South Khorasan budget data, and check the resolution.

\subsection{Mathematical Formulation}

The variables and parameters are presented in Table 1, 2 and 3 .

Table 1. Definition of the main variables model.

\begin{tabular}{ll}
\hline The main icon & Variable \\
\hline $\mathrm{X}_{\mathrm{t}}$ & University budget in year $\mathrm{t}$ \\
$X_{t c}$ & The central budget $\mathrm{c}$ in year $\mathrm{t}$ \\
$X_{\mathrm{tcu}}$ & The budget of unit $\mathrm{u}$ at center $\mathrm{c}$ in year $\mathrm{t}$ \\
$Y_{t}$ & The budget allocated in year $\mathrm{t}$ \\
$Y_{t p}$ & The budget allocated to the program $\mathrm{p}$ in year $\mathrm{t}$ \\
$Y_{\mathrm{tps}}$ & The budget allocated to the program $\mathrm{p}$ is a subprogram \\
$d_{r}^{+}$ & in year $\mathrm{t}$ \\
$d_{r}^{-}$ & Variable deviation from ideal (positive deviation) \\
\hline
\end{tabular}

Table 2. Definition of certain parameters.

\begin{tabular}{ll}
\hline The main icon & Define certain parameters (nominal) \\
\hline$U_{\mathrm{i}}$ & The utility of any cause in the objective function \\
$G_{2}$ & The optimum ratio of research budget to the total budget \\
$G_{4}$ & The optimal ratio of staff budget to total budget \\
$W_{t p}$ & The desirability of each RLS budget for program $\mathrm{p}$ in \\
\hline
\end{tabular}

Table 3. Define certain parameters.

\begin{tabular}{|c|c|}
\hline The main icon & Define certain parameters (nominal) \\
\hline$E_{t c u}$ & Unit performance $\mathrm{u}$ at the center $c$ in year $\mathrm{t}$ \\
\hline $\bar{U}_{t}^{y}$ & $\begin{array}{l}\text { The nominal amount of upper bound of the allocated } \\
\text { budget to the program in year } t\end{array}$ \\
\hline $\bar{L}_{t}^{y}$ & $\begin{array}{l}\text { The nominal amount of low bound allocated budget to } \\
\text { the all program in year } t\end{array}$ \\
\hline $\bar{U}_{t p}^{y}$ & $\begin{array}{l}\text { The nominal amount of the upper bound of the budget } \\
\text { allocated to the program pin year } t\end{array}$ \\
\hline $\bar{L}_{t p}^{y}$ & $\begin{array}{l}\text { The nominal amount of the low budget allocated to the } \\
\text { program pin year } t\end{array}$ \\
\hline $\bar{U}_{t p s}^{y}$ & $\begin{array}{l}\text { The nominal amount of high budget allocation to } \\
\text { subprogram } \mathrm{s} \text { to program } \mathrm{p} \text { in year } \mathrm{t}\end{array}$ \\
\hline $\bar{L}_{t p s}^{y}$ & $\begin{array}{l}\text { The nominal amount of the low budget allocation to } \\
\text { subprogram } \mathrm{s} \text { to program } \mathrm{p} \text { in year } \mathrm{t}\end{array}$ \\
\hline $\bar{U}_{t}^{x}$ & $\begin{array}{l}\text { The nominal amount of the upper limit can be } \\
\text { assigned to the central budget year } t\end{array}$ \\
\hline $\bar{L}_{t}^{x}$ & $\begin{array}{l}\text { The nominal amount of the low budget allocation to } \\
\text { the entire centers in year } t\end{array}$ \\
\hline $\bar{U}_{t c}^{x}$ & $\begin{array}{l}\text { Nominal value attributable to the high budget to center } \\
\mathrm{c} \text { in year } \mathrm{t}\end{array}$ \\
\hline $\bar{L}_{t c}^{x}$ & $\begin{array}{l}\text { The nominal amount of the low budget allocated to the } \\
\text { center in year } t\end{array}$ \\
\hline $\bar{U}_{t c u}^{x}$ & $\begin{array}{l}\text { The nominal amount of high budget allocation to the } \\
\text { unit } u \text { at the center } \mathrm{c} \text { the year } \mathrm{t}\end{array}$ \\
\hline $\bar{L}_{t c u}^{x}$ & $\begin{array}{l}\text { The nominal amount of low budget allocation to the } \\
\text { unit } u \text { at the center the year } t\end{array}$ \\
\hline
\end{tabular}

Through all the ideals in the university budgeting system and continuous interviews with officials, four main goals were identified and selected as searching ideals. Table 4 explains the ideal model.

Table 4. Goals in the model of performance-based budgeting.

\begin{tabular}{|c|c|c|}
\hline Number of ideal & Ideal Type & Defining ideal \\
\hline The first ideal & $\operatorname{Max}$ & $\begin{array}{l}\text { The aim of maximizing the utility of } \\
\text { budget allocating to programs }\end{array}$ \\
\hline The second ideal & $\operatorname{Max}$ & $\begin{array}{l}\text { The optimum ratio of research } \\
\text { budget to all program budgets }\end{array}$ \\
\hline The third ideal & $\operatorname{Max}$ & $\begin{array}{l}\text { The aim of maximizing the utility of } \\
\text { budget allocating to each unit }\end{array}$ \\
\hline The fourth ideal & Min & $\begin{array}{l}\text { The optimum ratio of support budget } \\
\text { to all program budgets }\end{array}$ \\
\hline
\end{tabular}

It should be noted that in the above tables, all uncertain parameters (upper and lower bounds) are also considered to be nominal. Thus, the nominal performance- based budgeting model (CPBB) can be written as follows:

$$
\begin{gathered}
\text { Min } \mathrm{Z}=\mathrm{U}_{1} \mathrm{~d}_{1}^{-}+\mathrm{U}_{2} \mathrm{~d}_{2}^{-}+\mathrm{U}_{3} \mathrm{~d}_{3}^{-}+\mathrm{U}_{4} \mathrm{~d}_{4}^{+} \\
\mathrm{S.t.} . \\
\left(\sum_{t=1}^{m} \sum_{p=1}^{n} W_{t p} Y_{t p}\right)+d_{1}^{-} \geq G_{1} ; \\
Y_{t 2}-G_{2} \sum_{p=1}^{P} Y_{t p}+d_{2}^{-} \geq 0 ; \\
\sum_{t=1}^{T} \sum_{c=1}^{C} \sum_{\mathrm{u}=1}^{U} E_{t c \mathrm{u}} X_{t c \mathrm{u}}+d_{3}^{-} \geq G_{3} ; \\
Y_{t 4}-G_{4} \sum_{p=1}^{P} Y_{t p}-d_{4}^{+} \leq 0 ; \\
X_{t}=\sum_{c=1}^{C} X_{t c} ; \\
X_{t c}=\sum_{u=1}^{U} X_{t c u} ; \\
Y_{t}=\sum_{p=1}^{\gamma} Y_{t p} ; \\
Y_{t p}=\sum_{s=1}^{\alpha} Y_{t p s} ; \\
\sum_{i=1}^{m} U_{i}=1 ; \\
\sum_{p=1}^{P} W_{t p}=1 ; \\
\bar{L}_{t}^{X} \leq X_{t} \leq \bar{U}_{t}^{X} ; \\
\bar{L}_{t c}^{X} \leq X_{t c} \leq \bar{U}_{t c}^{X} ; \\
\bar{L}_{t c u}^{X} \leq X_{t c u} \leq \bar{U}_{t c u}^{X} ; \\
\bar{L}_{t}^{Y} \leq Y_{t} \leq \bar{U}_{t}^{Y} ; \\
\bar{L}_{t p}^{Y} \leq Y_{t p} \leq \bar{U}_{t p}^{Y} ; \\
\bar{L}_{t p s}^{Y} \leq Y_{t p s} \leq \bar{U}_{t p s}^{Y} ; \\
\end{gathered}
$$

\subsection{The Robust Counterpart for PBB Model}

In order to the nominal robust, Bertsimas and Sim'model [8] is used here. This model is (CLB -RPBB) as follows:

$$
\operatorname{Min} Z=U_{1} d_{1}^{-}+U_{2} d_{2}^{-}+U_{3} d_{3}^{-}+U_{4} d_{4}^{+}
$$

S.t.

$$
\text { (1) - (10); }
$$




$$
\begin{aligned}
& Y_{t}+Z_{t} \Gamma_{t}+q_{t} \leq \bar{U}_{t}^{y} \\
& Z_{t}+q_{t} \geq \widehat{\bar{U}}_{t}^{y} \\
& Y_{t p}+Z_{t p} \Gamma_{t p}+q_{t p} \leq \bar{U}_{t p}^{y} \\
& Y_{t p s}+Z_{t p s} \Gamma_{t p s}+q_{t p s} \leq \bar{U}_{t p s}^{y} ; \\
& Z_{t p}+q_{t p} \geq \widehat{\bar{U}}_{t p}^{y} \\
& Z_{t p s}+q_{t p s} \geq \widehat{U}_{t p s}^{y} ; \\
& \bar{L}_{t}^{y} \leq Y_{t} \\
& \bar{L}_{t p}^{y} \leq Y_{t p} \\
& \bar{L}_{t p \mathrm{~s}}^{y} \leq Y_{t p \mathrm{~s}} \\
& X_{t}+Z_{t}^{x} \Gamma_{t}^{x}+r_{t} \leq \bar{U}_{t}^{x} \\
& Z_{t}^{x}+r_{t} \geq \widehat{\bar{U}}_{t}^{X} \\
& X_{t c}+Z_{t c}^{x} \Gamma_{t c}^{x}+r_{t c} \leq \bar{U}_{t c}^{x} ; \\
& Z_{t c}^{x}+r_{t c} \geq \widehat{U}_{t c}^{X} \\
& X_{t c \mathrm{u}}+Z_{t c \mathrm{u}}^{x} \Gamma_{t c \mathrm{u}}^{x}+r_{t c \mathrm{u}} \leq \bar{U}_{t c \mathrm{u}}^{x} ; \\
& Z_{t c \mathrm{u}}^{x}+r_{t c \mathrm{u}} \geq \widehat{\bar{U}}_{t c g}^{X} ; \\
& \bar{L}_{t}^{x} \leq X_{t} \\
& \bar{L}_{t c}^{x} \leq X_{t c} ; \\
& \bar{L}_{t c u}^{x} \leq X_{t c u} ;
\end{aligned}
$$

$q_{t} \geq 0, q_{t p} \geq 0, q_{t p s} \geq 0, r_{t} \geq 0, r_{t c} \geq 0, r_{t c u} \geq 0, Z_{t} \geq 0, Z_{t p} \geq$ $0, Z_{t p s} \geq 0, Z_{t c} \geq 0, Z_{t c \mathrm{u}} \geq 0, Z_{t}^{x} \geq 0, Z_{t c}^{x} \geq 0, Z_{t c u}^{x} \geq 0$

\section{Analysis and Discussion of Results}

The robust model presented in this study includes 73 variables and 115 constraints.

The main parameters in this model include the following:

- The coefficients of ideals in the objective function $\left(U_{i}\right)$ : using the ideas of college education and financial managers and using paired comparisons, each ideal weight is determined in Table 5.

Table 5. The weight of each ideal in the objective function.

\begin{tabular}{lllll}
\hline Ideal & First & Second & third & fourth \\
\hline Weight & $0 / 631$ & $0 / 151$ & $0 / 151$ & $0 / 067$ \\
\hline
\end{tabular}

In addition, the second and fourth ideal values were considered using the education and research managers' comments, and to determine the values of the first and third, the ideal models were solved for the first and second individually. The values of these ideals are presented in Table 6 .
Table 6. Ideals values (Figures 1000 Rials).

\begin{tabular}{ll}
\hline The number of ideal & The amount of ideal \\
\hline The first ideal & 36000 \\
The second ideal & $15 \%$ \\
The third ideal & 22000 \\
The fourth ideal & $7 \%$ \\
\hline
\end{tabular}

- The utility of budget allocation to programs $\left(W_{t p}\right)$ : using the ideas of education and college finance managers and using paired comparisons, the weight of each case was determined in table 7 .

Table 7. The weight of each program is the first ideal.

\begin{tabular}{llll}
\hline Program & Educational & Research & Cultural and extra curricula \\
\hline Weight & $0 / 493$ & $0 / 493$ & $0 / 014$ \\
\hline
\end{tabular}

- Coefficients of performance for each unit $\left(E_{t c u}\right)$ : using DEA, the efficiency of each unit was calculated. The data required about the inputs and outputs was gathered PNU of South Khorasan. For this purpose, four inputs and four outputs were considered in table 8 as follows:

Table 8. Inputs and outputs in a DEA model.

\begin{tabular}{ll}
\hline Input & Output \\
\hline The number of faculty members & Work shops \\
The number of students in master & The number of graduate students in \\
degree course for each center & each center \\
The number of undergraduate & The number of bachelors who \\
students & passed the employing test \\
Grant faculty & Scores of articles, translation and \\
& writing \\
\hline
\end{tabular}

- The length of the symmetric range of uncertain parameters: As mentioned earlier, the upper bound of the budget is considered as uncertain parameters. After studying the budget changes domain in recent years, the length of the symmetric range in which nominal parameters swing is given in table 9 .

Table 9. Length of domain of uncertain parameters.

\begin{tabular}{ll}
\hline Uncertainties & Length parameter \\
\hline$\widehat{U}_{t}^{x}$ & $2 / 5$ of the centers total budget \\
$\widehat{U}_{t c}^{x}$ & $2 / 5$ budget of the center $c$ \\
$\widehat{U}_{t c u}^{x}$ & $2 / 5$ budget of unit u in center $c$ \\
$\widehat{U}_{t}^{y}$ & $2 / 5$ of total budget \\
$\widehat{U}_{t 1}^{y}$ & $2 / 3$ of the total education budget \\
$\widehat{U}_{t 2}^{y}$ & $1 / 5$ of the total research budget \\
$\widehat{U}_{t 3}^{y}$ & $2 / 3$ of the total welfare-service budget \\
$\widehat{U}_{t 1 \mathrm{~s}}^{y}$ & $2 / 3$ budget of subprogram s of training program \\
$\widehat{\bar{U}}_{t 2 \mathrm{~s}}^{y}$ & $2 / 5$ budget of subprogram s of research program \\
$\widehat{U}_{t 3 \mathrm{~s}}^{y}$ & $2 / 3$ budget of subprogram s of welfare-service program \\
\hline
\end{tabular}

\section{Results}

In Sim's model robust parameters are determined to let decision-makers control the desired protection level. Accordingly, the 10 protection levels is determined and is solved by LINGO software. 
Table 10. The total deviation from the goals and robust objectives with different protection levels (Figures 1000 Rials).

\begin{tabular}{lll}
\hline Protection level & $\begin{array}{l}\text { The total amount of } \\
\text { deviations }\end{array}$ & The objective function \\
\hline 1 & 224623 & 21441815 \\
2 & 224773 & 21012315 \\
3 & 258487 & 20582915 \\
4 & 297260 & 20153327 \\
5 & 341849 & 19733816 \\
6 & 393126 & 19301815 \\
7 & 452094 & 18872700 \\
8 & 519908 & 18442692 \\
9 & 597894 & 18017292 \\
10 & 687578 & 17587792 \\
\hline
\end{tabular}

As this table shows, by increasing the levels of protection, both the total amount of devotion and the value objective function get worse that is reasonable and consistent with the robustness of the model; when the decision maker wants to take more uncertainty of the model, the answers will be more conservative. The increasing conservatism leads to a reduction in the amount of the budget being allocated. Budgeting programs and the total budget for centers will be presented in the following.

Table 11. Results of the proposed budget with different levels of protection based model (Figures 1000 Rials).

\begin{tabular}{llll}
\hline $\begin{array}{l}\text { Protection } \\
\text { level }\end{array}$ & $\begin{array}{l}\text { Cultural-extra } \\
\text { curricular budget }\end{array}$ & $\begin{array}{l}\text { Management } \\
\text { program budget }\end{array}$ & $\begin{array}{l}\text { Curriculum } \\
\text { budget }\end{array}$ \\
\hline 1 & 2799476 & 5348210 & 9911710 \\
2 & 2739181 & 5304001 & 9795471 \\
3 & 2678592 & 5259647 & 9674021 \\
4 & 2617584 & 5215260 & 9550021 \\
5 & 2557394 & 5170760 & 9427521 \\
6 & 2497196 & 5126602 & 9312732 \\
7 & 2436898 & 5082113 & 9191243 \\
8 & 2376699 & 5037624 & 9069457 \\
9 & 2316399 & 4992835 & 8946989 \\
10 & 2256101 & 4951537 & 8823989 \\
\hline
\end{tabular}

\section{Conclusion}

In recent decades, new methods of planning and performance management for universities require extensive research in this field. By reviewing the literature, there was no mathematical model that can check dual budgeting structure based on performance budgeting at university simultaneously. So the aim of this study is to provide a robust model of PBB in the University in which on the one hand, fund allocation to universities is based on performance and the results of previous programs, and on the other hand, considering the uncertainty of the upper bound, the assigned budget will be improved through using the robust model. By taking various measures at the university, the PBB programming model was designed. The most important factor in designing the model is using a DEA approach to determine the importance of each unit and center of university for allocating budget.

PNU is structured in such a way that there is a distance between the centers, units and headquarters of the province. Also a part of the budget is set by the ministry of science and thus is out of the university control, however, the results are similar to the universities with a centralized structure and more authority in budget allocation. Therefore, since there is cost of transportation between the province headquarters and units, better solution can be achieved for budget allocation by taking the upper and lower uncertain bounds.

After designing the model, in order to deal with uncertainty in the parameters of the upper bound of the budget, we considered the length of range changes for this parameter, wrote the robust model and PNU of South Khorasan were analyzed at the operational level. By studying this model, it was observed that the higher the level of protection in the model, the more conservative the decisionmakers are to allocate found in the centers and units that correspond with the robust model. In the traditional model of budgeting, allocation of the budget is based on factors such as number of students, faculty, staff, and there is no focus on the issue of the effectiveness and results of the program centers. The only way to rewarded good performance and reproach poor performance is to allocate budget on performance. Since each year only a portion of the budget is achieved, the budget decision makers can take advantage of the results of this model, and allocate the budget to the programs and centers according to the available budget, and through using the robust model, manage the uncertainties in upper bounds of budget properly at the university.

\section{References}

[1] Azar, A., Khadivar, A., Naseri, A., \& Rostami, A. (2011). A linear programming model with robust approach for performance-based budgeting (PBB). Governmental management issue, 3, 93-120.

[2] Azar, A., Khadivar, A., Naseri, A., \& Rostami, A. (2011). Robust mathematical modeling, new approach in Iran public budgeting. Journal of teacher humanities- management researches in Iran, 15, 1-19.

[3] Ben-Tal, A., Den Hertog, D., De Waegenaere, A., Melenberg, B., \& Rennen, G.(2013). Robust solutions of optimization problems affected by uncertain probabilities. Management Science, 59, 341-357.

[4] Ben-Tal, A., Den Hertog, D., \& Vial, J.-P. (2015). Deriving robust counterparts of nonlinear uncertain inequalities. Mathematical programming, 149, 265-299.

[5] Ben-Tal, A., \& Nemirovski, A. (1998). Robust convex optimization, 23, 769-805.

[6] Ben-Tal, A., \& Nemirovski, A. (1999). Robust solution to uncertain linear programs, Operation research letters, 25, 1-13.

[7] Ben-Tal, A., \& Nemirovski, A. (2000). Robust solutions of linear programming problems contaminated with uncertain data, 88, 411-424.

[8] Bertsimas, D., \& Sim, M. (2004). The price of the robustness. Operations research, 52, 35-53. 
[9] Charness, A., \& Cooper, W. W. (1971). Studies in mathematical and managerial economics. North-Holland Publishing Company, 166-180.

[10] Caballero, R., Golache, T., Gomez, T., Molina, J., \& Torrico, A. (2001). E_cient assignment of _nancial resources within a university system: study of the University of Malaga. European Journal of Operational Research; 133, 298-309.

[11] Gabrel, V., Murat, C., \& Thiele, A. (2014). Recent advances in robust optimization: An overview. European journal of operational research, 235, 471-483.

[12] Kwak, N. K., \& Lee, C. lee. (1998). A multi-decision-making approach to university resource allocation and information in frastructure planning. European Journal of Operational Research, 110, 234-242.

[13] Lee, M. S. (2010) Performance-oriented budgeting in public universities: The case of a national university in Japan. The journal of nance and management in colleges and universities, in Japan, 43-60.

[14] Min, H. (1988). Three-phase hierarchical allocation of university resources via interactive fuzzy goal programming. Socio-Economic Planning Sciences, 22, 229-239.

[15] Najafi, S. (2011). Mathematical modeling budgeting in the public section: robust approach. Master thesis industrial engineering, Faculty of Engineering, University of Shahed.

[16] Soyster, A. (1973). Convex programming with set-inclusive constrains and applications to inexact linear programming, 21, 1154-1157.

[17] Shim J. P,.\& Lee, M. S. (1984). Zero-base budgeting: Dealing with conicting objective. Long Range Planning, 17, 103-110.

[18] Zanakis, S. H. (1991). A multi criteria approach for library needs assessment and budget allocation. Socio-Economic Planning Science, 251, 233-245. 